\title{
Meditaciones sobre la norma VIII del Título Preliminar del Código Tributario
}

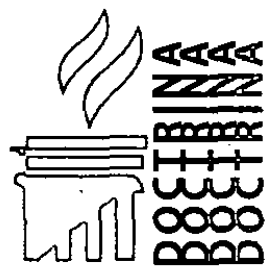

\section{Jorge Bravo Cuca}

Abogado por la Universidad de Lima . Doctor en Derecho Empresarial por la Universidad de Sevilla. Profesor de Derecho Tributario de la Pontificia Universidad Católica del Perú.

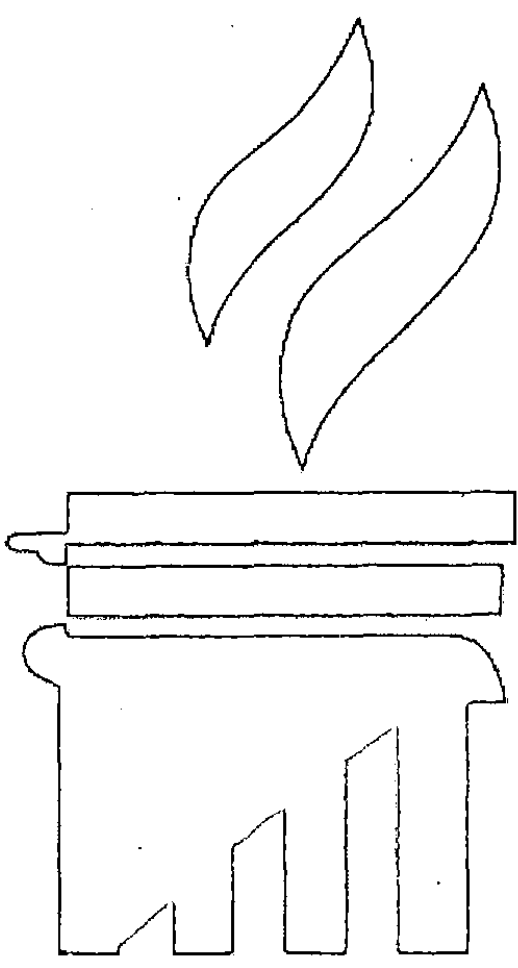

SUMARIO:

I. Introducción.

II. Un intento de respuesta:

1. ¿Qué institución juridica regula dicha norma?;

2. ¿Cuál es la forma como debe aplicarse dicha norma?;

3. ¿Cuál es la diferencia entre los negocios en fraude a la ley y los negocios con simulación relativa? ¿Es posible el combate a los negocios en fraude a la ley a través del segundo párrafo de la Norma VIII?;

4. ¿El segundo párrafo de la Norma VIII contiene un precepto con rango constitucional? Dicha norma isupone un conflicto con el principio de reserva de ley previsto en el artículo 74 de la Constitución Politica del Perú? ¿La aplicación de dicha norma contraviene al principio de autonomía privada y a libertad de contratación contenida en el artículo 62 de la Constitución?;

5. ¿Puede la Administración Tributaria en aplicación del segundo párrafo de la Norma VIII desconsiderar un negocio jurídico con simulación relativa, o requiere previamente que los órganos jurisdiccionales hayan declarado la simulación, a través de una sentencia ejecutoriada?;

6. ¿Vulnera la calificación del hechọ imponible el principio de autonomía privada? 


\section{INTRODUCCIÓN}

La Norma VIII del Título Preliminar del Código Tributario, dispone en su segundo párrafo lo siguiente:

"Para determinar la verdadera naturaleza del hecho imponible, la Superintendencia Nacional de Administración Tributaria-SUNAT-tomará en cuenta los actos, situaciones y relaciones económicas que efectivamente realicen, persigan o establezcan los deudores tributarios".

Es objeto del presente trabajo responder las siguientes cuestiones relacionadas con el párrafo antes citado:

1. ¿Qué institución jurídica regula dicha norma?

2. ¿Cuál es la forma como debe aplicarse dicha norma?

3. ¿Cuál es la diferencia entre los negocios en fraude a la ley y los negocios con simulación relativa? ¿Es posible el combate a los negocios en fraude a la ley a través del segundo párrafo de la Norma VIII?

4. ¿El segundo párrafo de la Norma VIII contiene un precepto con rango constitucional? Dicha norma ¿supone un conflicto con el principio de reserva de ley previsto en el artículo 74 de la Constitución Política del Perú? ¿Contraviene a la libertad de contratación contenida en el artículo 62 de la Constitución?

5. ¿Puede la Administración Tributaria en aplicación del segundo párrafo de la Norma VIII desconsiderar un negocio jurídico con simulación relativa, o requiere, previamente que los órganos jurisdiccionales hayan decla- rado la simulación a través de una sentencia ejecutoriada?

6. ¿Vulnera la calificación del hecho imponible el principio de autonomía privada?

\section{UN INTENTO DE RESPUESTA}

\section{1. ¿Qué institución jurídica regula dicha norma?}

El segundo párrafo del Título Preliminar del Código Tributario contiene una norma de calificación del hecho imponible. Dicha norma faculta a la Administración Tributaria a subsumir los hechos realizados por los contribuyentes en las hipótesis de incidencia de normas tributarias, previamente a haberlos calificado como imponibles.

Como lo enseña GARCÍA NOVOA, la calificación es:
"(...) un conjunto de operaciones que se rea- lizan por parte de los aplicadores del Derecho con el fin de analizar desde el punto de vista juridico aquellas circunstancias del mundo real que pueden ser incluidas en los supuestos de hecho de la norma. (...) Junto con la interpre- tación, cuyo objeto, como vimos, son normas $y$, por tanto, hipótesis abstractas previstas en las mismas, la fijación y calificación de hechos constituye una fase previa e imprescindible del proceso de aplicación del derecho objetivo $<<e n$ permanente interacción con la norma $>>$ ".

La calificación del hecho imponible es una interpretación de los hechos. No solo es susceptible de interpretación el derecho, sino todo aquello que lleva un revestimiento lingüistico. $Y$ los hechos son narraciones de eventos en lenguaje; por lo tanto son susceptibles de ser interpretados. ${ }^{2}$ En ese sen-

1 GARCIAA NOVOA, César, La cláusula antielusiva en la nueva Ley General Tributaria, Marcial Pons, 2004, p. 234.

2 CARVALHO, Paulo de Barros, Derecho tributario. Fundamentos jurídicos de la incidencia. "HABERMAS trabaja efec tuando la distinción entre hechos y objetos de la experiencia. Los hechos serían los enunciados lingüisticos sobre las cosas y los acontecimientos, sobre las personas y sus manifestaciones. Los objetos de la experiencia son aquello acerca de lo cual hacemos afirmaciones, aquello sobre lo que emitimos enunciados". Editorial Ábaco, 2002, p. 117. 
tido, calificar es interpretar los hechos, y verificar si respecto de ellos se produce la subsunción y la incidencia de alguna norma tributaria.

Puede decirse entonces, que la apliçación del derecho supone dos procesos indivisibles: a) la interpretación de las normas jurídicas y b) la calificación de los hechos. La calificación es la actividad con la que la aplicación del derecho culmina.

En ese orden de ideas, la calificación de los hechos como imponibles, no es una facultad exorbitante ni especial, sino propia del acreedor tributario y de su administración tributaria e inherente a su condición. A su vez, la calificación del hecho imponible es un medio para cumplir con una obligación que le es propia: la obligación de hallar la verdad material. ${ }^{3}$ Lo que no permite la calificación del hecho imponible, es la calificación del hecho en base a su realidad económica, pues ello supondria una interpretación económica del hecho imponible, siendo que únicamente es posible interpretar los hechos desde la perspectiva normativa, aplicando los métodos de interpretación permitidos por el Derecho. GONZÁLEZ GARCíA dice con contundencia que no es la realidad económica la que calificamos, sino esa realidad en la medida que ha sido trasladada a la norma jurídica. ${ }^{4}$

En caso de que los hechos susceptibles de ser calificados se encuentren revestidos de negocios jurídicos, la facultad de calificación supondrá una evaluación del negocio jurídico y de su causa típica, a los efectos de descartar la presencia de una causa simulada (causa simulationis), que es un ejemplo de causa falsa.

La evaluación de la causa supone la valoración de si el fin perseguido por las partes se adecúa a la causa-fin del negocio jurídico empleado, valoración que se hace dentro de los márgenes de la ley.

Y asi lo hareconocidó el propio Tribunal Fiscal a través de la Resolución del Tribunal Fiscal No. 06686-4-2004, al sostener que la norma en comentario recoge el criterio de calificación económica, facultad que lleva implícita la de dejar de lado la formalidad jurídica del acto o negocio realizado por el contribuyente, cuando este resulte manifiestamente incongruente con los actos o negocios jurídicos efectivamente realizados, esto es, cuando se advierta que la causa de los mismos es simulada.

Como es sabido, a través de la simulación se aparenta realizar el supuesto de hecho de una norma (hecho simulado), encubriendo la realización de un hecho real (hecho disimulado) $o$ inexistente. Mientras en la simulación relativa existen dos negocios jurídicos (uno simulado y otro disimulado), en la simulación absoluta existe un solo negocio jurídico (simulado). La posibilidad de calificar el hecho imponible solo se advierte en casos de negocios con simulación relativa, toda vez que en el caso de la simulación absoluta no existe negocio alguno que calificar.

Como hemos dicho en anterior oportunidad, el negocio jurídico simulado es ineficaz mientras que el negocio jurídico disimulado es válido. El negocio jurídico disimulado no es un acto oculto sino el acto verdadero por el cual las partes han querido vincularse. El negocio jurídico disimulado es válido pero se le aplicarán las normas imperativas que se quisieron eludir. ${ }^{5}$

Teniendo en cuenta lo antes dicho, puede concluirse que en aplicación de la facultad de cali-

3 Ley 27444. Artículo IV.-

"1.11. Principio de verdad material.-En el procedimiento, la autoridad administrativa competente deberá verificar plenomente los hechos que sirven de motivo a sus decisiones, para lo cual deberá adoptar todas las medidas probatorias necesarias autorizadas por la ley, aun cuando no hayan sido propuestas por los administrados o hayan acordado eximirse de ellas".

4 GONZALEZ GARCÍA, Eusebio, La interpretación de las normas tributarias, Aranzadi, Pamplona, 1997, p. 70.

5 BRAVO CUCCI, Jorge y MORALES HERVIAS, Rómulo, El negocio jurídico en fraude a la ley entre el derecho civil y el derecho tributario: una nueva visión para un viejo problema. En: Revista Vectigalia No. 2.

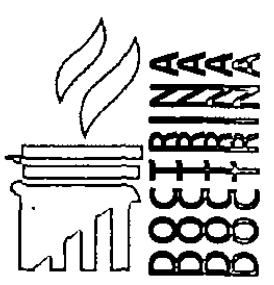

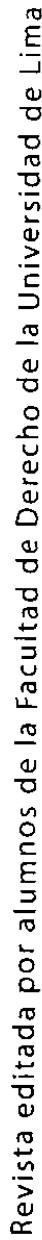


ficación del hecho imponible, la Administración Tributaria tiene la obligación de determinar la verdadera naturaleza del hecho imponible, para lo cual debe tener en cuenta los actos, situaciones y relaciones económicas que efectivamente realicen, persigan o establezcan los deudores tributarios, esto es, atender a las vicisitudes que afectan la existencia del negocio. Ello supone que en un caso en el que la Administración Tributaria determine un negocio simulado (que encubre uno disimulado), aplique la norma tributaria al negocio jurídico efectivamente perseguido por el contribuyente (el negocio disimulado). los requisitos de sustancia y de forma de este último". tercero]. simulación". fiscalizado, si existe discrepancia con la calificación efectuada por la Administración Tributaria.

3. ¿Cuál es la diferencia entre los negocios en fraude a la ley y los negocios con simulación relativa? ¿Es posible el combate a los negocios en fraude a la ley a través del segundo párrafo de la Norma VIII?

Suele decirse que los negocios en fraude a la ley se diferencian de los negocios con simulación relativa, en que estos últimos presentan una realidad aparente al exterior, contraria con la verdadera voluntad de las partes, en donde se manifiesta un negocio oculto, característica que no se presenta en el fraude a la ley, en el que si bien hay dos negocios jurídicos, el negocio jurídico coberturado es válido, siendo ineficaz el negocio de cobertura.

Debemos decir que el Código Civil peruano ha regulado la simulación relativa conforme al modelo del Código Civil italiano. En ese sentido, el negocio jurídico simulado es ineficaz y el negocio jurídico disimulado es válido. El negocio jurídico disimulado no es un acto oculto sino el acto verdadero por el cual las partes se han querido vincular. Entonces, caben dos efectos jurídicos en el caso del negocio jurídico en fraude a la ley que contiene dos actos. El negocio jurídico simulado es ineficaz conforme a los artículos $191^{6}$ y $194^{7}$ del Código Civil. El negocio jurídico disimulado es válido pero se le aplicarán las normas imperativas que se quisieron eludir.

6 Primer párrafo del artículo 1414 del Código Civil italiano: "Efectos de la simulación entre las partes. - Si las partes han querido celebrar un contrato diverso del aparente, tiene efectos entre ellas el contrato disimulado, siempre que subsistan

[Artículo 191 del Código Civil peruano.- Cuando las partes han querido concluir un acto distinto del aparente, tiene efecto entre ellas el acto ocultado, siempre que concurran los requisitos de sustancia y forma y no perjudique el derecho de

7 Primer párrafo del artículo 1415: "Efectos de la simulación respecto a terceros.- La simulación no puede oponerse, nipor las partes contratantes, ni por sus causahabientes ni por los acreedores del enajenante simulado, a los terceros que de buena fe hubieren adquirido derechos del titular aparente, sin perjuicio de los efectos de la inscripción de la demanda de

[Artículo 194 del Código Civil peruano.-La simulación no puede ser opuesta por las partes nipor los terceros perjudicados a quien de buena fe y a título oneroso haya adquirido derechos de titular aparente]. 
Teniendo en cuenta que tanto el negocio jurídico en fraude de ley como el negocio jurídico con simulación relativa tienen una misma estructura: un negocio simulado (ineficaz) y un negocio disimulado (válido), la reacción que el ordenamiento jurídico tributario prevé ante ambas situaciones no tiene por qué ser distinta.

Un negocio jurídico en fraude de ley no es un negocio jurídico distinto pero equivalente al previsto en la norma jurídica defraudada, con lo que su corrección no requiere de la creación analógica de una norma ad-hoc. Decimos esto porque se suele afirmar -y asi lo afirma el Tribunal Fiscal en la Resolución del Tribunal Fiscal No. 06686-4-2004- que la corrección del fraude de ley en general y la del fraude a la ley tributaria en particular, se hace a través de la analogía. Como es sabido, la analogía no es un método de interpretación de normas sino un procedimiento que sirve para integrar el Derecho, allí donde se advierta una laguna normativa o segmento de la realidad social no regulado por alguna norma jurídica. La analogía consiste en aplicar la consecuencia normativa de una norma jurídica a un hecho no contemplado (implícita o explícitamente) en su hipótesis de incidencia, pero que es similar en sus elementos esenciales al que sí se encuentra contemplado, lo que en rigor significa efectuar una labor normativa.

Corresponde determinar si en un supuesto de fraude a la ley tributaria existe una laguna normativa. ${ }^{8}$ Si se sostiene que quien realiza un ' hecho en fraude a la ley tributaria realiza un "hecho equivalente" al hecho imponiblè y ese hecho no está comprendido en alguna otra norma tributaria, podría concluirse que se está ante una laguna normativa. $Y$ en ese escenario, pretender incluir tal "hecho equivalente" en la hipótesis de incidencia de la norma tributaria implicaría recurrir a la analogía, lo que vulneraría el principio de legalidad y la prohibición de aplicación analógica en materia tributaria. Pero tal línea argumentativa pierde consistencia en caso que sí exista una norma jurídica que se aplique -de forma menos gravosa- sobre el "hecho equivalente", pues allí sería patente la falta de una laguna normativa que requiera ser regulada a través de la integración analógica.

Contrariamente a lo expuesto precedentemente, creemos que quien realiza un negocio en fraude a la ley tributaria no realiza un "hecho equivalente" sino el mismo hecho imponible, solo que pretende coberturarlo artificiosamente a través de negocios simulados para evitar su configuración. En rigor, quien realiza un negocio en fraude a la ley no llega a eludirla -la norma incide indefectiblemente en el plano abstracto--, simplemente utiliza artificios para ocultar su aplicación frente a terceros. ${ }^{9}$ Por lo tanto, en un supuesto de fraude a la ley tributaria no hay una laguna normativa, pues el hecho en fraude a la ley sí cuenta con una norma que lo regula (la norma tributaria defraudada), y en tal secuencia lógica, no hay cabida para la analogía ${ }^{10}$, método de integración del derecho que consiste en crear una norma para aplicarla a un hecho que no contaba con regulación normativa.

La 'corrección del fraude a la ley tributaria no requiere recurrir al expediente de creaŕ una nueva norma o ampliar analógicamente una ya existente para gravar el hecho en fraude a la ley. El mecanismo de corrección consiste en que la Administración Tributaria, empleando la facultad de calificación del hecho imponible,

8 DIEZ-PICAZO, Luis y GULLÓN, Antonio, Sistema de Derecho Civil, Volumen l. "La expresión «laguna» se utiliza, por supuesto, en un sentido metafórico, para aludir a la existencia de posibles oquedades o vacios. El punto de referencia de los mismos es tanto una ley concreta y determinada como el ordenamiento legislativo. La laguna se presenta (...) cuando nos encontramos con una inexistenciä de ley aplicable al punto controvertido." Editorial Tecnos, 1994، p. 176.

9 Por ello la expresión "elusión tributaria" es equivoca pues su significado literal supone la no realización del hecho imponible, lo que no ocurre en el caso materia de análisis.

Según el Diccionario de la Real Academia "eludir" es evitar con astucia una dificultad o una obligación.

10 CRICENTI, Giuseppe, I contratti in frode alla legge, Giuffrè Editore, Milán, 1996, pp.13-15. 
ante la utilización de una forma o ropaje jurídi$\mathrm{co}$, prescinda de ella y haga como si se hubiera utilizado la forma juridica adecuada, aplicando la norma tributaria pertinente."

Por eso corresponde aseverar una vez más, que en la corrección del fraude a la ley tributaria no se requiere recurrir a la analogía, pues ni hay una laguna normativa, ni se crea una nueva norma al corregir la situación de fraude. ${ }^{12}$ En ese sentido, opinamos que la facultad de calificación del hecho imponible contenida en el segundo párrafo de la Norma VIII resulta de aplicación para calificar tanto los negocios en fraude a la ley, como los negocios con simulación relativa.

\section{4. ¿El segundo párrafo de la Norma VIII} contiene un precepto con rango constitucional? Dicha norma isupone un conflicto con el principio de reserva de ley previsto en el artículo 74 de la Constitución Política del Perú? ¿La aplicación de dicha norma contraviene al principio de autonomía privada y a libertad de contratación contenida en el artículo 62 de la Constitución?

La facultad de calificación del hecho imponible -al igual que cualquier otra facultad inherente al acreedor tributario-deriva de la propia potestad tributaria que detenta el Estado, y por lo tanto de la Constitución Política del Perú. Quien tiene la potestad tributaria detenta el crédito tributario en contraposición al deudor tributario, quien tiene el deber de contribuir al sostenimiento del gasto público en función a su capacidad contributiva. Siendo ello así, tanto el acreedor como el deudor tributario, tienen en el texto constitucional el sustento para la aplicación del derecho (interpretación y calificación): mientras que el acreedor lo hace en función a la potestad tributaria, el deudor tributario lo hace sobre la base del deber constitucional de contribuir.
Suele decirse que para que la Administración Tributaria pueda establecer la existencia del hecho imponible a partir de la consideración económica, deberían suceder dos cosas: a) constitucionalizarla y b) establecer que mediante ella se puede establecer la existencia del hecho imponible (y no solo para determinar su verdadera naturaleza) como dice textualmente el Código Tributario.

Nótese, sin embargo, que la "consideración económica del hecho imponible" es cosa distinta a la calificación del hecho imponible. En efecto, al amparo del segundo párrafo de la Norma VIII, la Administración Tributaria no puede calificar el hecho desde su realidad económica; lo que puede sí, es calificar el hecho desde la perspectiva normativa, analizando si la causa del negocio jurídico es la prevista por el ordenamiento jurídico para ese negocio, o si se trata de una causa simulada. Para ello, debe hacer uso de los medios probatorios (contratos, informes, facturas, libros contables, títulos valores, pericias) a los efectos de demostrar lo que a su criterio es "la verdadera naturaleza del hecho imponible". Es importante entender que el uso de los medios probatorios -como es el caso de las facturas y los libros contables- a los efectos de develar la verdadera causa del negocio jurídico, no supone una consideración económica del mismo.

Por tanto, reconocer que el segundo párrafo de la Norma VIII faculta solo a determinar la verdadera naturaleza del hecho imponible y no autoriza a la Administración Tributaria a establecer la existencia del hecho imponible alli donde las formas utilizadas por las partes no le dan vida, es un razonamiento correcto, y no se contrapone a la posibilidad de calificar los hechos imponibles y recalificar los negocios juridicos con simulación relativa.

En cuanto a la segunda interrogante, debemos ser enfáticos en que no existe ningún conflicto entre la referida facultad de calificación del

11 RUIZ ALMENDRAL, Violeta y SEITZ, Georg, Op. Cit., p. 23.

12 QUERALT, Juan Martín, LOZANO SERRANO, Carmelo y otros, Curso de Derecho financiero y tributario, EditorialTecnos, Madrid, 2000, p. 196. 
hecho imponible y el principio de reserva de ley. Se trata de dos instituciones absolutamente complementarias y armónicas, pues la facultad de calificación supone la subsunción de un hecho en un precepto normativo que ha sido insertado en el ordenamiento a través de una Ley o Decreto Legislativo. Cuando el acreedor tributario ejerce la facultad de calificación del hecho imponible, lo hace dentro del marco del principio de reserva de ley.

Lo que sí constituye una vulneración del principio de reserva de ley, es la "consideración económica del hecho imponible", pues no supone la subsunción del hecho a la hipótesis de incidencia contenida en una norma tributaria (que es precisamente de lo que trata la calificación del hecho imponible), sino la creación de una nueva hipótesis de incidencia por vía de analogía.

Finalmente, debemos referirnos a si la calificación del hecho imponible por parte de la Administración Tributaria vulnera el principio de autonomía privada recogido en el artículo 62 de la Constitución. La autonomía privada tienè dos dimensiones: una individual (autorregulación de los intereses de las partes contratantes) y otra social (efectos para los terceros). Es en esa dimensión social, en que el negocio jurídico califica como un hecho susceptible de ser calificado como imponible por la Administración Tributaria, sin que dicha calificación suponga una intromisión en el proceso de autorregulación de intereses por parte de los contratantes. Sostener tesis contraria, supondría la imposibilidad de llevar a cabo el proceso de aplicación de las normas tributarias que contengan en sus hipótesis de incidencia la realización de negocios jurídicos, pues en dicho entendimiento, la Administración Tributaria carecería de la facultad de subsumir el hecho en el precepto normativo.
5. ¿Puede la Administración Tributaria en aplicación del segundo párrafo de la Norma VIII desconsiderar un negocio jurídico con simulación relativa, o requiere previamente que los órganos jurisdiccionales hayan declarado la simulación, a través de una sentencia ejecutoriada?

Es importante tener en cuenta que la facultad de calificación del hecho imponible, en el caso de negocios con simulación relativa, no supone la declaración de inexistencia o invalidez del negocio jurídico, ni requiere como presupuesto para su aplicación que dicha inexistencia o invalidez haya sido previamente declarada por algún órgano jurisdiccional, a través de una sentencia que cause dicho estado. Como bien lo indica Ferreiro Lapatza, la referida facultad no supone la calificación de los negocios jurídicos realizados por los administrados de acuerdo con los elementos de la norma civil, comercial o societaria correspondiente, ni pretende otros efectos distintos a los relevantes para efectos tributarios. ${ }^{13}$ Y ello por cuanto, como lo expresa Souto Maior Borges; al Derecho Tributario le importan, propiamente los resultados tributarios alcanzados y no los efectos jurídicos instaurados entre los particulares. ${ }^{14}$

La calificación de los hechos imponibles únicamente persigue la identificación del negocio jurídico que en realidad se ha realizado, pero a los efectos de subsumirlo en la hipótesis de incidencia de una norma tributaria. Si como producto de la calificación y soportado en los medios probatorios pertinentes, la Administración Tributaria advierte una causa simulada, los efectos de tal calificación no serán otros que la aplicación de la norma tributaria que se considera aplicable al negocio disimulado. A mayor abundamiento, Torres Taveira menciona que en el derecho comparado, los ordenamientos

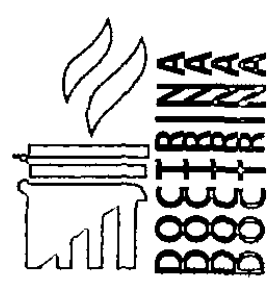

13 FERREIRO LAPATZA, José Juan, Economia de opción, fraude de ley, sanciones y delito fiscal. En: Revista de Técnica Tributaria, No. 52, p. 44.

14 SOUTO MAIOR BORGES, José, Lancamento Tributario, Malheiros Editores, p. 353. 
tributarios prevén la aplicación de las normas tributarias sobre negocios jurídicos, con prescindencia de si fueron declarados nulos o inválidos por los órganos jurisdiccionales. ${ }^{15}$

Como lo entiende García Novoa, la calificación de los hechos imponibles y la recalificación de negocios jurídicos con simulación relativa, es una de las manifestaciones de la autotutela del crédito tributario $^{16}$-toda vez que el acreedor tributario no requiere acudir a los tribunales civiles para que se declare la simulación- y la misma se limita, como actuación de calificación que es, a asegurar el cumplimiento de las obligaciones tributarias que verdaderamente existan y no tiene efectos más allá de lo estrictamente tributario. ${ }^{17}$ Como en toda manifestación de la autotutela del crédito tributario, el ordenamiento jurídico otorga al contribuyente las garantías procesales para cuestionar la calificación del hecho imponible.

\section{6. ¿Vulnera la calificación del hecho imponible el principio de autonomia privada?}

La facultad de calificación del hecho imponible -al igual que cualquier otra facultad inherente al acreedor tributario-deriva de la propia potestad tributaria que detenta el Estado, y por lo tanto de la Constitución Política del Perú. Quien tiene la potestad tributaria, detenta el crédito tributario en contraposición al deudor tributario, quien tiene el deber de contribuir al sostenimiento del gasto público en función a su capacidad contributiva. Siendo ello asi, tanto el acreedor como el deudor tributario, tienen en el texto constitucional el sustento para la aplicación del derecho (interpretación y calificación): mientras que el acreedor lo hace en función a la potestad tributaria, el deudor tributario lo hace sobre la base del deber constitucional de contribuir.

Al respecto, corresponde determinar si la calificación del hecho imponible por parte de la Administración Tributaria, vulnera el principio de autonomía privada recogido en el artículo 62 de la Constitución.

A decir de Torres Taveira, el principio de autonomía privada se descubre como principio de Derecho Constitucional Civil que consiste en el poder atribuido por la Constitución a las personas, individual o colectivamente, para determinar consecuencias jurídicas como resultado de comportamientos libremente asumidos $o$, de un modo más objetivo, como el poder otorgado constitucionalmente a los particulares para que estos puedan crear normas jurídicas, para la constitución de situaciones jurídicas, fundando derechos subjetivos sobre bienes disponibles, bajo tutela y garantía del Estado. ${ }^{18}$

En términos etimológicos, "autonomía» (auto + nómos), quiere decir capacidad de autogobernarse, facultad que posee una determinada persona o institución para establecer sus propias normas, libre de cualquier subordinación. Traida al ámbito jurídico, la «autonomía privada» se presenta como una calificación de la facultad que las personas tienen para, mediante el ejercicio de la voluntad libre y sin vicios, crear entre si normas jurídicas, de modo que instituyan actos con efectos jurídicamente vinculantes.

15 TORRES TAVEIRA, Heleno, Direito Tributario e Direito Privado. Autonomia, simulación, elusión tributaria, Editora dos Tribunais, 2003, p. 378.

16 CALVO ORTEGA, Rafael, Derecho Tributario, Parte General. "La protección del crédito tributario en beneficio del acreedor ha sido una constante en la historia de los tributos. Su permanencia en los ordenamientos jurídicos y su reflejo en varias figuras concretas hace que pueda hablarse de un verdadero principio. Su justificación es la misma que hemos visto anteriormente al estudiar los privilegios de la Administración: la gestión de los intereses generales". Editorial Civitas, p. 107.

17 GARCÍA NOVOA, César, El fraude de ley en el Derecho Tributario, Marcial Pons, 2003.

18 TORRES TAVEIRA, Heleno, Direito Tributario. Autonomia Privada, Simulacao, Elusao Tributaria, Editora dos Tribunais, 2003, p. 107. 
La autonomía privada tiene dos dimensiones: una individual (autorregulación de los intereses de las partes contratantes) y otra social (efectos para los terceros). Es en esa dimensión social, en que el negocio jurídico encuadra como un hecho susceptible de ser calificado como imponible por la Administración Tributaria, sin que dicha calificación suponga una intromisión en el proceso de autorregulación de intereses por parte de los contratantes, ni una vulneración al principio de autonomía privada. Ello porque la autonomía privada supone una autorregulación dentro de un marco normativo que otorga a los negocios jurídicos ciertas causas, objetos y formas preestablecidas, que son las que el ordenamiento jurídico prevé. La autonomía privada no es una potestad irrestricta ni arbitraria, siendo que su ejercicio abusivo o a través de negocios anómalos (con simulación relativa o en fraude a la ley) con el fin de eludir la aplicación de normas tributarias, permite su recalificación por parte del acreedor tributario.

Sostener tesis contraria, supondría reconocer la imposibilidad de llevar a cabo el proceso de aplicación de las normas tributarias que contengan en sus hipótesis de incidencia la realización de negocios jurídicos, pues en dicho errado entendimiento, la Administración Tributaria carecería de la facultad de calificar el hecho imponible y subsumirlo en el precepto normativo, lo que haría impracticable su labor e inútil su existencia.

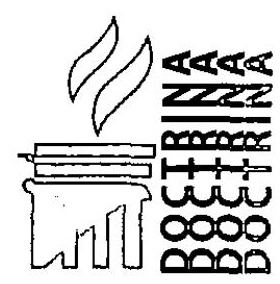

